\title{
A hunt for OM45 synthetic petite interactions in Saccharomyces cerevisiae reveals a role for Miro GTPase Gem1 in cristae structure maintenance
}

\author{
Antonina Shvetsova ${ }^{1}$, Ali Masud ${ }^{1}$, Laura Schneider ${ }^{1}$, Geoffray Monteuuis ${ }^{1}$, Ulrich \\ Bergmann $^{1}$, Ilkka Miinalainen ${ }^{1}$, J. Kalervo Hiltunen ${ }^{1}$, and Alexander Kastaniotis ${ }^{1}$ \\ ${ }^{1}$ University of Oulu
}

April 7, 2021

\begin{abstract}
Om45 is a major protein of the yeast outer mitochondrial membrane under respiratory conditions. However, the cellular role of the protein has remained obscure. Previously, deletion mutant phenotypes have not been found, and clear amino acid sequence similarities that would allow inferring its functional role are not available. In this work, we describe synthetic petite mutants of UGO1 and GEM1 that depend on the presence of OM45 for respiratory growth, as well as the identification of several multicopy suppressors of the synthetic petite phenotypes. In the analysis of our mutants, we demonstrate that Om45 and Gem1 have a collaborative role in the maintenance of mitochondrial morphology, cristae structure, and mitochondrial DNA maintenance. A group of multicopy suppressors rescuing the synthetic lethal phenotypes of the mutants on non-fermentable carbon sources additionally supports this result. Our results imply that the synthetic petite phenotypes we observed are due to the disturbance of the inner mitochondrial membrane and point to this mitochondrial sub-compartment as the main target of action of Om45, Ugo1, and the yeast Miro GTPase Gem1.
\end{abstract}

\section{Hosted file}

Final-0M45_references_31.12.2020.pdf available at https://authorea.com/users/406322/articles/ 517029-a-hunt-for-om45-synthetic-petite-interactions-in-saccharomyces-cerevisiae-

reveals-a-role-for-miro-gtpase-gem1-in-cristae-structure-maintenance 
A

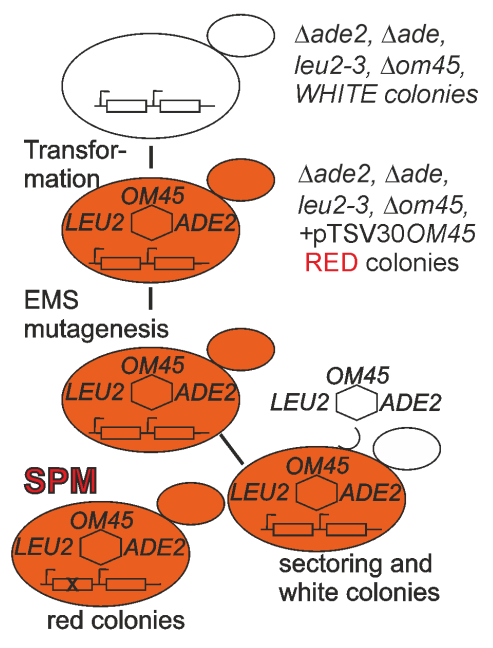

D

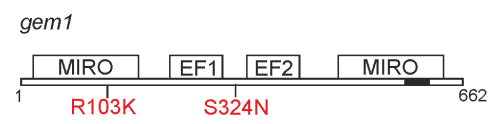

$$
\text { ugo } 1
$$

B $\triangle \circ \mathrm{m} 45$, gem1 (R103K)

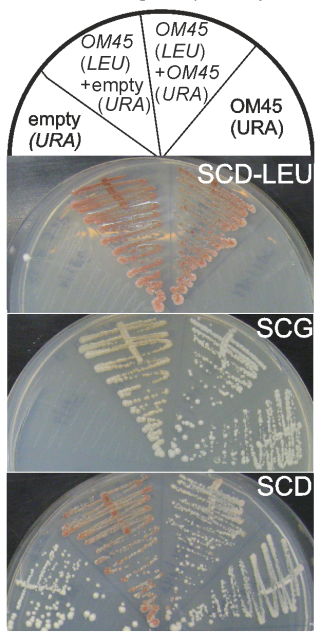

C $\Delta o m 45, u g o 1(p 189 L)$

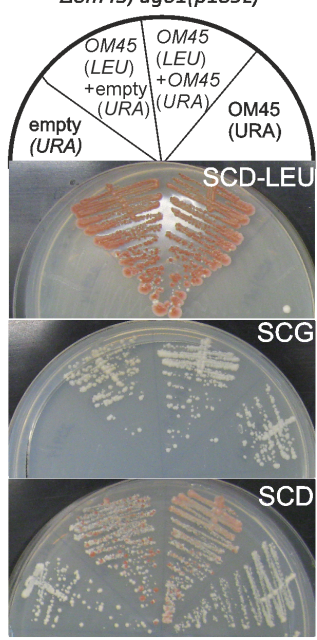

E

\begin{tabular}{|l|l|l|}
\hline Gene hit & Mutant sequence & WT sequence \\
\hline gem1 & \multicolumn{2}{|l|}{ catttcaaatcctggggttgaat } \\
(R103K) & H F K S L G L N & H F R S L G L N \\
\hline gem1 & gacacttccaatgtggaattgagc & \multicolumn{2}{|c|}{ gacacttccagtgtggaattgagc } \\
(S324N) & D T S N V E L S & D T S S V E L S \\
\hline ugo1 & atagatttctttctcatagaaagg & atagatttctttcccatagaaagg \\
(P189L) & I D F F L I E R & I D F F P I E R \\
\hline
\end{tabular}




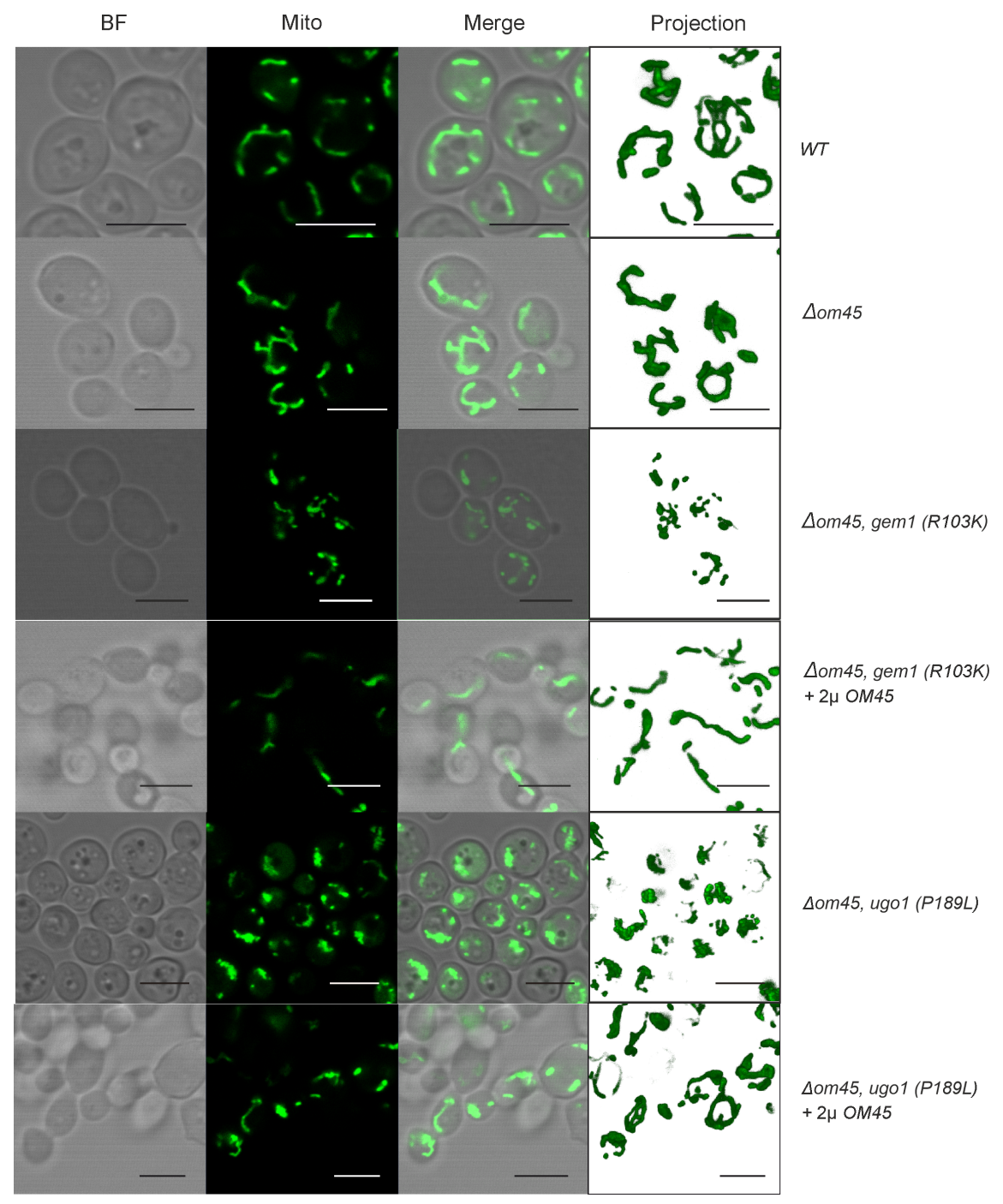




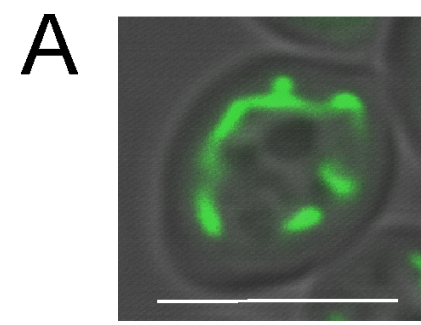

Tubules

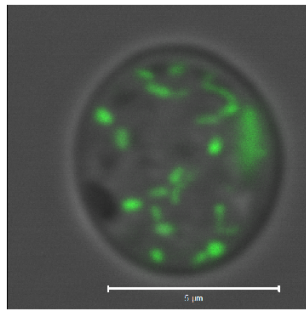

Fragmented

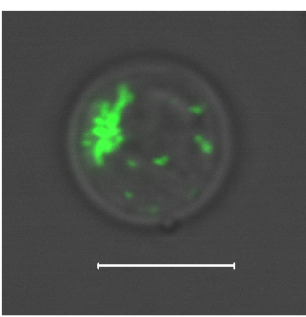

Aggregated fragments

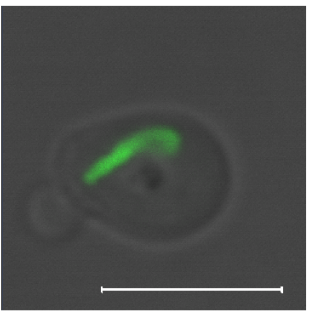

Tubules

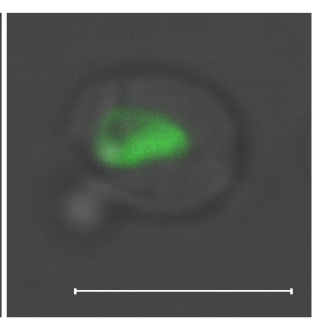

Clusters

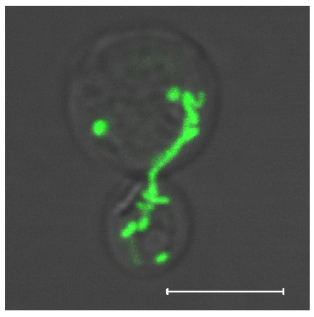

Winding

tubule

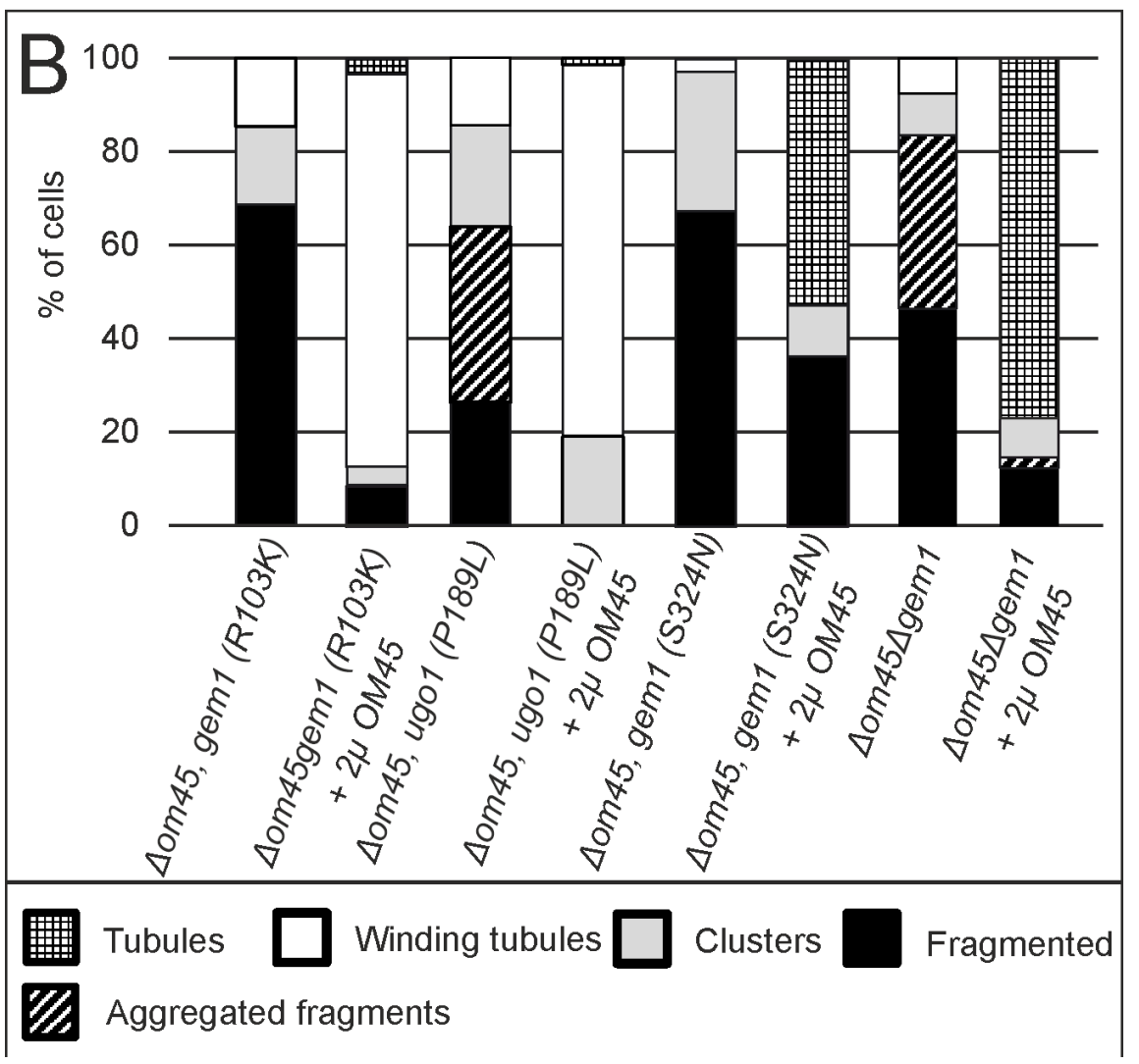




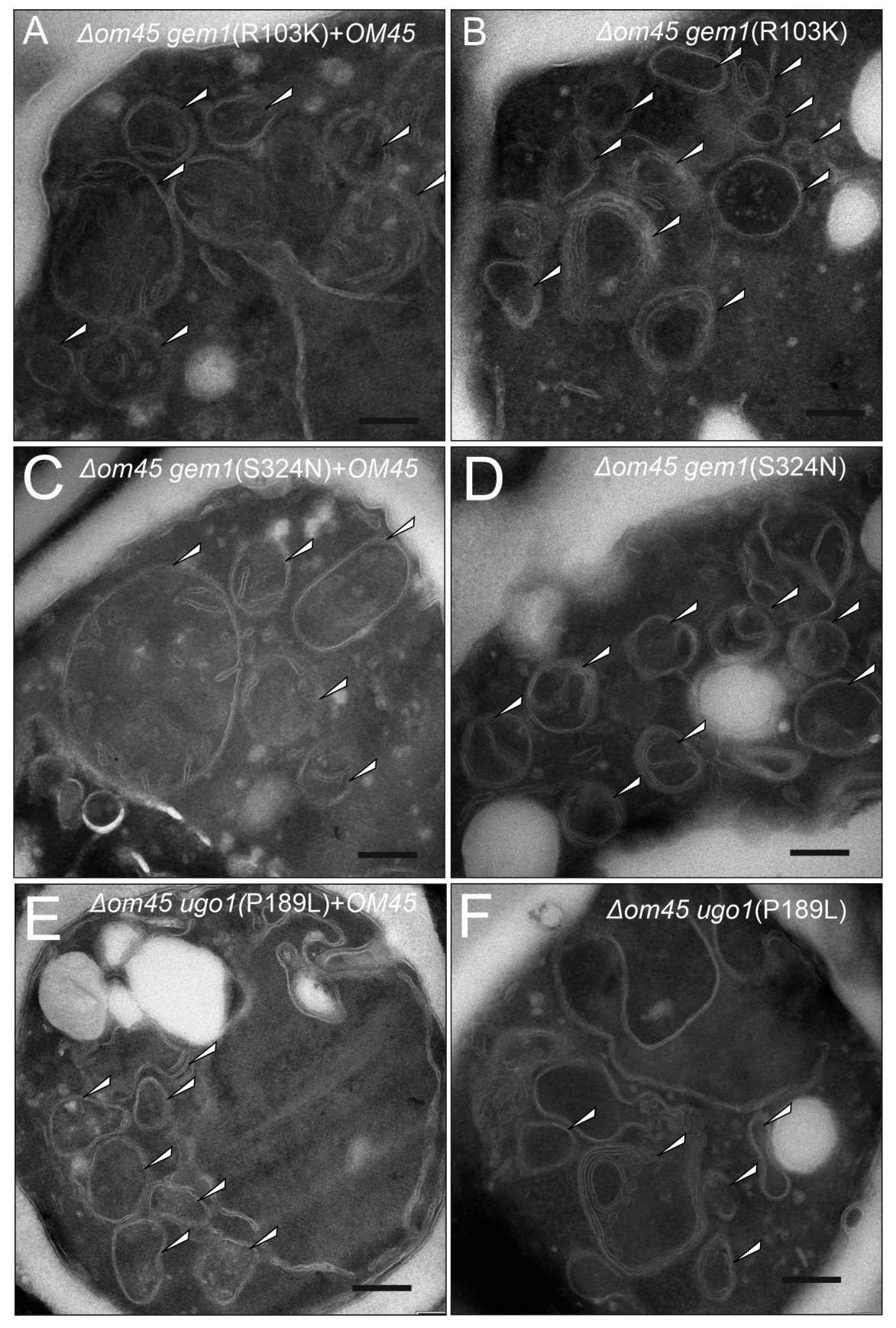





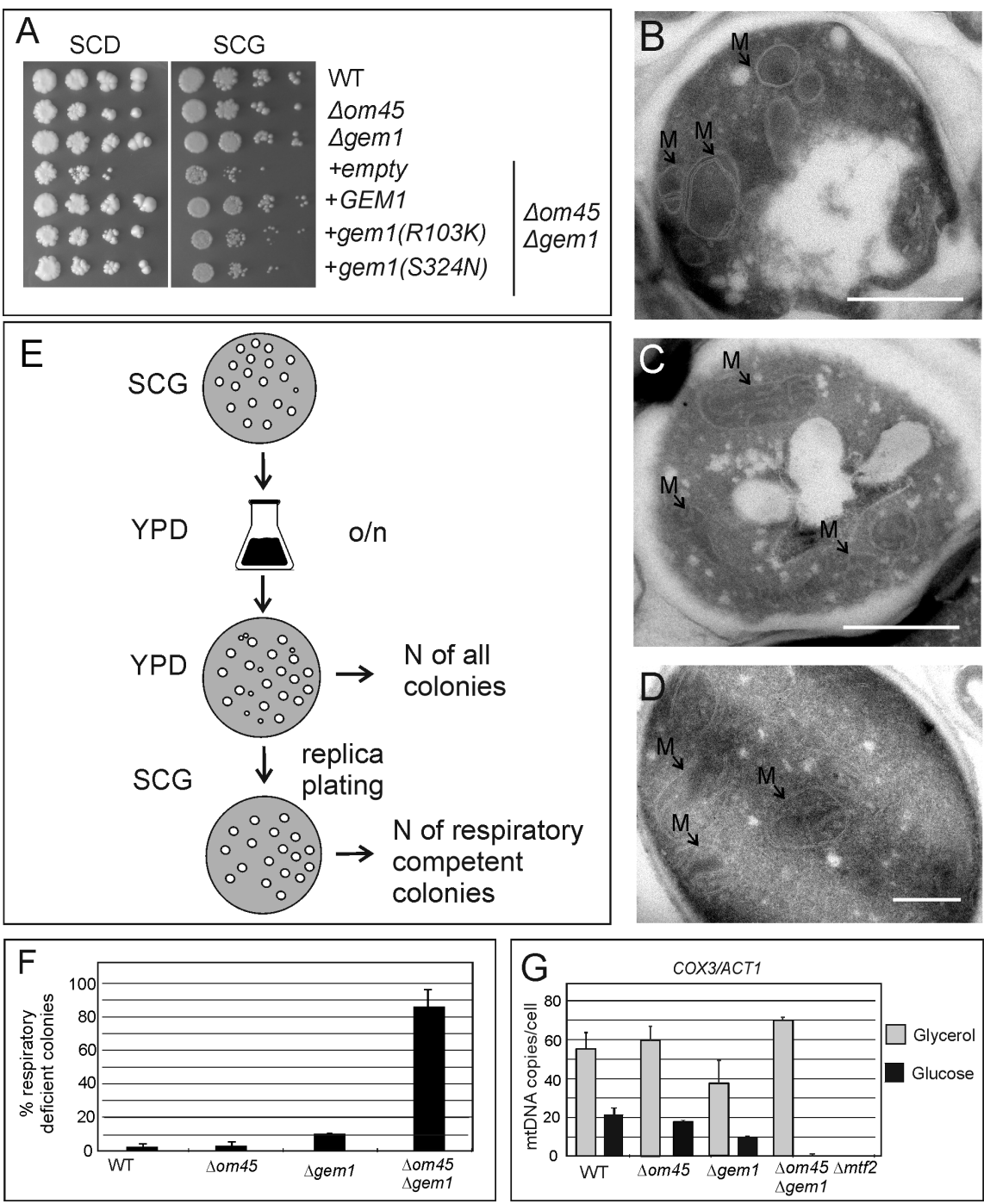


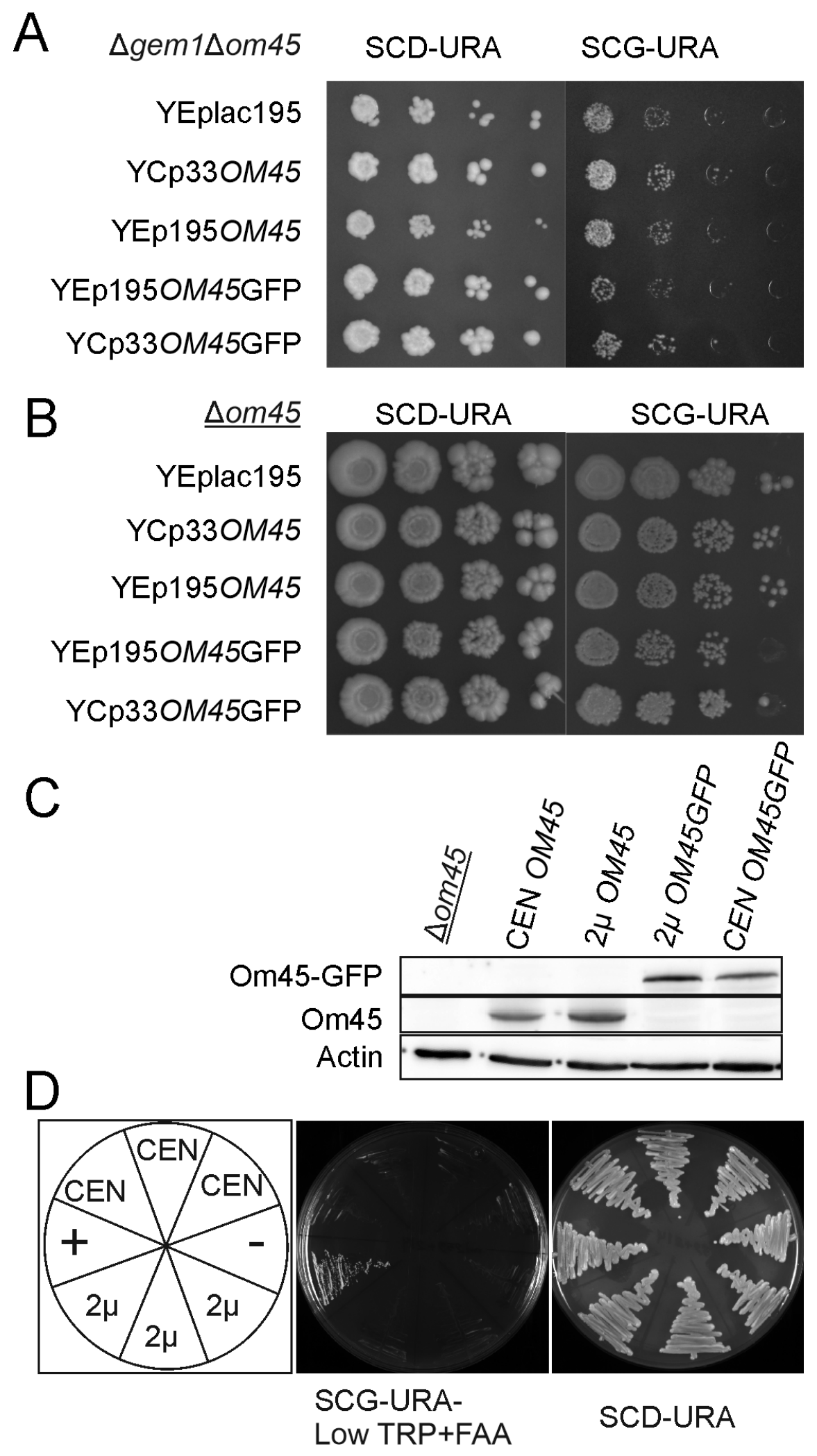

